\title{
Research on the Introduction Policy of High-tech Talents of Taiwan*
}

\author{
Jianping Huang \\ FuZhou University of International Studies and Trade \\ Fuzhou, China 350200
}

\begin{abstract}
High-tech talent is the first key to the development of science and technology. For this reason, this article mainly elaborates the general situation of Fujian's hightech talents, analyzes the difficulties of Fujian's introduction policy of Taiwan's high-tech talents, and proposes proposals for resolving the introduction of Taiwan's high-tech talents.
\end{abstract}

Keywords-Taiwan; high-tech talents; introduction policy

\section{INTRODUCTION}

High-tech talent is the key to improving the ability of independent innovation. And it is one of the main players in giving full play to the primary productive forces of science and technology and the role of talents as the first resource. The practice and research results of the introduction of wisdom for more than 30 years have also shown that the introduction of intellectual resources is a way to promote the rapid economic and social development of the region with less expenditure, higher returns, and quicker results than the simple introduction of technology and equipment. In September 2016, the Fujian Provincial Party Committee issued the "Opinions on Deepening the Implementation of the Reform of the Talent Development System and Mechanism" and put forward the implementation of the "Double Hundred Plan" for the introduction of Taiwan's high-level talents, striving to introduce and confirm 100 high-level Taiwanese talents every year. In 4 years, it would separately select 100 Taiwanese talents to have relevant policy treatment. Therefore, under the current circumstances, the vigorous introduction of Taiwan's high-tech talent is one of the important ways for Fujian to realize the leap-forward development of both sides of the Taiwan Straits.

\section{STATUS OF HIGH-TECH TALENTS OF FUJIAN PROVINCE}

Science and technology talent resources have been relatively scarce. Since the founding of new China, Fujian province only have more than 6000 scientific and technological personnel. In recent years, based on the needs of economic and social development, Fujian should increase investment in education and science and technology. And the total number of scientific and technological personnel

*It is supported by think tank of science and technology association of Fujian province in 2017 (decision consultation). The research is on the introduction policy of high-tech talents of Taiwan (project number: FJKXB1717)

\author{
Lihua Huang \\ FuZhou University of International Studies and Trade \\ Fuzhou, China 350200
}

continues to grow. The total number of persons engaged in scientific and technological activities grew from 179,000 in 2010 to 253,000 by 2015 , an increase of 41.3 percent. The research and development activity is the core of the scientific research activity. And the research and development personnel are the core part of the scientific and technological talents. The research and development personnel gained a rapid increase by practicing the idea that "science and technology is the first productive force and talent is the first resource" in Fujian province. The population of Fujian province grew from 76,700 in 2010 to 126,600 in 2015, an increase of 65.1 percent. With the increase of the number of scientific and technological talents and the improvement of the quality of scientific and technological talents, the scientific and technological output quality in Fujian province has been further improved. The number of patent applications and authorizations, as well as the number of scientific and technological papers in Chinese periodicals, has increased rapidly. Among them, the number of applications for invention patents, which can represent the quality of patents, has increased by 2.5 times from 5117 in 2010 to 17663 in 2015. And the number of applications for invention patents can represent the quality of patents. Also, it has increased by 3.7 times from 1,224 in 2010 to 5,730 in 2015. The amount of technical market contract increased from 3,566 million yuan in 2010 to 5,386 million yuan in 2010, an increase of 51 percent. With the development of social economy in Fujian province and the increase of financial funds, the government quickens the pace of constructing scientific research environment. Local financial expenditure on science and technology has been further increased. And it continues to increase the research and development funds. R \& D research and development funds accounted for a further increase in the GDP of Fujian province from 170.09 billion yuan in 2010 to 39.293 billion yuan in 2015, an increase of 131 percent. These data fully shows that Fujian province has made unremitting efforts to improve the scientific research environment. And they have also made some commendable achievements.

\section{DIFFICULTIES IN THE INTRODUCTION OF HIGH-TECH TALENTS OF TAIWAN}

\section{A. Policy Advocacy}

Policy advocacy and policy absorption is a mutual process. On the one hand, the publisher of the policy would 
make the announcement through the intermediary media. And the world would know the information. On the other hand, the recipients of the information obtain the actual situation and information of the policy through the same channels. Some units do not know much about the policy of introducing high-tech talents issued by the government. On the one hand, the communication between these units and the government is not enough. On the other hand, there are great differences in the communication channels between the units and the government. And there are also great differences in the medium used for publication and acceptance.

\section{B. Policy Formulation}

The policy pertinence is not strong. And the policy pertinence mainly displays in the pertinence of introduction object of science and technology talents, the pertinence of policy content and the talents demand and so on. The policy does not attract many personnel. And the high-tech talents are scarce resources. The cost of introducing high-tech talent is relatively high. It must be extremely cautious when introducing high-tech talent, which leads to too many narrow conditions when formulating the policy of introducing hightech talent of Taiwan.

\section{Policy Implementation}

The implementation of the policy is cumbersome. And judging from the implementation of the policy on the introduction of high-tech talents of Taiwan, it takes a long time for the entire policy to go from notice, review, and reward. In the course of the implementation of the policy, due to various objective factors, part of the reward conditions cannot be realized or deferred. And public confidence and the attraction of the introduction policy of high-tech talent of Taiwan greatly reduced. The evaluation system of policy implementation has not been formed. It has not yet formed the evaluation system of the implementation of the policy and the effectiveness of the introduction of high-tech talents.

\section{Policy Support}

The policy system has poor compatibility. At this stage, we often formulate high-tech talent policy from the single policy point of view. Usually, different policies have been issued, and different executive departments are also fighting in their own separate. They don't coordinate all kinds of policies. It has not paid enough attention to the training of high-tech talents of Taiwan. And the units have not paid enough attention to them. Especially, the understanding of high-tech talents of Taiwan has yet to be further improved. The supporting services are inadequate. There are also some problems such as housing problems, employment problems of family members, problems of children attending school, and so on.

\section{SUGGESTIONS ON THE OPTIMIZATION OF INTRODUCTION POLICY OF TAIWAN'S HIGH-TECH TALENTS}

\section{A. To Strengthen the Organization of Institutions and Perfect the Linkage among Departments}

1) To strengthen organizational leadership: It is necessary to break the traditional talent introduction management mode, introduce more demand factors such as market, social environment and industry, form multidepartment linkage, clarify clear the functions of each department, do well in the work of each department, such as goal formulation, policy propaganda, online declaration, technical review, policy implementation and tracking service, and solve all kinds of contradictions and difficulties in the recruitment work in time.

2) To deepen understanding: It should break through the bondage of traditional ideas and concepts. To deepen the understanding is not only to deepen the understanding of the importance of talents among government departments, functional organizations and personnel. It is also to deepen the understanding of the value of talents among the market, the employing units and the high-level talents. It should deepen the understanding of the market and talent. And the market should recognize the demand. The employer should see the demand, the direction and the future plan clearly.

3) Multi-regional competition and cooperation: The multi-regional talent competition is the manifestation of incentive means. Importantly, the target we aim at is the introduction of high-level talent, which is characterized by high cost, high scarcity and large demand. And it means the link of multi-region and multi-industry. The same imported high-tech talent of Taiwan can be used by multi-regions. And they would exert infinite creativity.

\section{B. To Improve the Way of Propaganda and Create Good Atmosphere}

1) To strengthen the construction of network platform: The introduction policy of Taiwan's high-tech talents does not have a proprietary website or column. The release of policy and the disclosure of information is relatively scattered and slow. In view of this, it is suggested to establish a special website for talent introduction in the name of the government. They could open up different columns, give full play to the advantages of the network, and connect with various functional departments in realtime and on-the-spot. At the same time, the network platform should be extended to the area of talent and industry. We will further expand the influence of the network. All departments at all levels can interact with each other, exchange information, talents, projects and technologies.

2) To enrich the means of propaganda: The government should organize and implement the publicity plan for scientific and technological talents, open up columns and hold training for scientific and technological talents. The 
government should attach importance to strengthen the theoretical study of talent work, and actively use the research results to guide and enhance the talent work. They should vigorously propagandize the advanced model and excellent model of talent work, and actively create social environment respecting the talents. As imported talents, when they get the publicity, they should first focus on the environment. Therefore, while publicizing the policy, we should focus more on creating the social and human environment for the talents. The government should infect them with the typical examples of our own talents, and attract them with the existing social environment.

\section{To Define the Policy Direction and Revise the Introduction Policy of High-tech Talents of Taiwan}

1) To focus on sustainability: At present, all kinds of policies have three to five years in general. With the increase of economic development and the talent development demand, the implementation of talent policy will certainly have changes in three to five years. To maintain the sustainability of the talent policy requires us to plan the content of the policy reasonably. When formulating the policy, we should set out from the future development, coordinate the relationship among the development of the fund, the talent demand, the industrial structure and the regional economy. Also, the government should arrange the various resources reasonably to make the policy.

2) To strengthen the incentive of entrepreneurial talents: The incentive to start-up talent also remains in the home fees, project funding and other forms. The control means is relatively simple. It still has great limitations in the scientific research fund subsidies, office space subsidies and talent placement. The government's initial investment in Taiwan's scientific and technological talents has certain risks. When we formulate policies, we should make a risk assessment on the investment of entrepreneurial talents and the expectation of the future, and make a pre-judgment on their potential and strength. In particular, for scientific and technical personnel in some small and medium-sized enterprises, the government can't judge the value of talent or enterprise through the short-term benefit and economic indicators. The introduction of high-level talent is a longterm process. And it needs constant incentive, support, service to create more social value. At the same time, we should also attach importance to the training of scientific and technological talents. At present, the policy often leaves the opportunity of talent exchange and training to experts with high respect or entrepreneurs with certain strength and status and high-level talents. However, it neglects the object that needs to be trained most. It should formulate a policy that is more advantageous to the exchange of talent training. It also should encourage the talents to study further and cultivate the high-level talents in the future.

3) To ensure financial investment, enhance the attraction and feasibility of policies: According to Maslow's hierarchy of needs and GRE theory, it must meet the various needs of talent, and Taiwan's high-tech talent policy could play its role. The various needs are based on adequate and reasonable financial investment. The influence of same geographical environment and different treatment on the development of talent is different. Of course, we cannot increase the investment in talent introduction unlimitedly. From a rational point of view, the government should appropriately increase the financial investment in talent introduction. They should meet the needs of talent, and enhance their competitiveness. From the classification of talents, we should also match the balance of talent investment from different angles and different categories. And then, it would rationalize the talent structure.

\section{To Pay Attention to Supporting Construction and Raise the Service}

1) To improve the training ability: The government would increase funding for key projects for high-tech talent of Taiwan, declare major science and technology and industrialization projects for Taiwan's high-tech talent, give priority to setting up projects to support them, and use the implementation of projects to promote the innovative ability of the training objects. Special allowances should be given to high-level talents who are particularly outstanding. To give full play to the advantages of resources to cultivate talents. We should give full play to the advantages, focus on strengthening the training of high-level scientific and technological personnel in key industries and key fields, and focus on doing a good job in the professional training and academic training of Taiwan's scientific and technological personnel. At the same time, it should use international and domestic talent training resources to provide high-level talents with opportunities. And these high-level talents would participate in various international academic conferences and academic exchanges activities. Also, it could recommend high-level scientific and technological talents to domestic and international well-known universities for further study.

2) To upgrade tracking services: The introduction of high-tech talents from Taiwan requires preferential policies, space for entrepreneurial development and good services. For the different values and life ideas of Taiwan's high-tech talents, the targeted "one-stop" and "nanny" service should be formed to change the former passive service mode. It should actively contact, speak, and think about what they want.

\section{CONCLUSION}

Under the background of the construction of both sides of the Taiwan Straits, Fujian province has gained many good policies. And these policies would be tried first in Taiwan. At the same time, there are many similarities between Taiwan and Fujian province, such as geographical proximity, consanguinity, inheritance of culture, connection of business and law. Especially after the "three links" between the two 
sides of the strait, the one-day life circle between the two sides of the strait has become the reality. Therefore, the introduction of high-tech talents from Taiwan is an important way for Fujian province to bring in scientific and technological talents and develop its scientific and technological strength. Therefore, great efforts have been made to bring in high-level talents from abroad. It is necessary to give full play to the talent policy, deepen the talent exchange and cooperation between Fujian and Taiwan, and play an important role in promoting the introduction of high-tech talents and the development of economy of Fujian province.

\section{REFERENCES}

[1] Li Chunhao. Demand and trend of China's innovation driven strategy for the development of science and technology talents [J].Science and Technology Management Research, 2016(15)

[2] Zhu Junwen. Research evolution of the international mobility of foreign scientific and technological talents [J].Scientific Studies. 2016(05) 